\title{
Maternal and neonatal plasma antioxidant levels in normal pregnancy, and the relationship with fatty acid unsaturation
}

\author{
Gerard S. Oostenbrug*, Ronald P. Mensink†, Monique D. M. Al, Adriana C. van Houwelingen \\ and Gerard Hornstra \\ Department of Human Biology, Maastricht University, Universiteitssingel 50, 6229 ER, Maastricht, The Netherlands
}

(Received 9 May 1997-Revised 28 January 1998 - Accepted 4 February 1998)

\begin{abstract}
During pregnancy, maternal plasma concentrations of the peroxidation-susceptible polyunsaturated fatty acids (polyenes) increase. In addition, the proportion of polyenes is higher in neonatal plasma than in maternal plasma. To study whether these increased amounts of polyenes affect antioxidant levels, we measured lipid-soluble antioxidants in maternal and neonatal plasmas obtained during thirty-five normal pregnancies. These values were then related to the degree of phospholipid-fatty acid unsaturation. Maternal plasma levels of tocopherols and lutein increased during pregnancy, as assessed at 14, 22, and 32 weeks of gestation. However, $\beta$-carotene levels decreased, and levels of other carotenoids remained unchanged. Retinol levels were only decreased at 32 weeks of gestation. The value for $\alpha$-tocopherol : phospholipid-polyene unsaturation index (UI) also increased during pregnancy, despite the observed increase in UI. Corresponding ratios for several carotenoids and retinol, however, decreased during pregnancy. After delivery, maternal plasma levels of $\delta$-tocopherol and $\beta+\gamma$-tocopherol, as well as $\beta+\gamma$-tocopherol: UI values, were lower than values at 32 weeks of gestation. Umbilical-cord plasma antioxidant levels and antioxidant: UI values, except retinol:UI, were significantly lower than maternal values. Significant and consistent cord $v$. maternal correlations were observed for plasma levels of $\beta+\gamma$ tocopherol, lutein and $\beta$-carotene, but not for $\delta$-tocopherol, $\alpha$-tocopherol, lycopene, $\alpha$-carotene, and retinol. In conclusion, although during pregnancy maternal plasma tocopherol levels increased concurrently with, or more than, fatty acid unsaturation in plasma phospholipids, the decrease in carotenoid: UI values during gestation, the decrease in maternal plasma levels of $\delta$-tocopherol and $\beta+\gamma$-tocopherol after delivery, and the low neonatal antioxidant levels merit further investigation.
\end{abstract}

Pregnancy: Fatty acid unsaturation: Antioxidants

Results from a prospective survey have shown that in pregnant women the total amount of fatty acids in plasma phospholipids increase by $51 \%$ from week 10 to week 40 of gestation (Al et al. 1995). The largest increases were noticed in the concentrations of saturated $(+57 \%)$ and monounsaturated $(+65 \%)$ fatty acids, but $n-6(+44 \%)$ and $n-3$ $(+41 \%)$ polyunsaturated fatty acids levels were also significantly increased. In addition, the proportion of polyunsaturated fatty acids was found to be higher in neonatal plasma than in maternal plasma. Since polyunsaturated fatty acids are very susceptible to oxidation, these changes may affect the plasma antioxidant status.

Several studies have shown that maternal plasma levels of the lipid-soluble antioxidant vitamin $\mathrm{E}$ also increase during pregnancy (Hågå et al. 1982; Mino \& Nagamatu, 1986; Uotila et al. 1991). Increases in maternal plasma vitamin $\mathrm{E}$ levels during pregnancy coincide with increased amounts of various plasma lipid classes (Mino \& Nagamatu, 1986), and plasma vitamin E levels standardized for plasma total lipid (Mino \& Nagamatu, 1986), cholesterol (Jagadeesan \& Prema, 1980a; Uotila et al. 1991), or LDL (Hågå et al. 1982) levels appear to remain constant during pregnancy. However, declining levels of triacylglycerol-standardized plasma vitamin E levels during pregnancy have been reported also (Jagadeesan \& Prema, 1980a). Reports on total carotenoid levels and vitamin A (retinol) during pregnancy are inconclusive (Morse et al. 1975; Panth et al. 1990), and information about individual carotenoids during pregnancy is scarce. In addition, the degree of unsaturation of the plasma lipids has not been taken into account in these studies.

In the newborn, plasma antioxidant levels have been found to be low compared with maternal levels (Jagadeesan \& Prema, 1980b; Martinez et al. 1981; Hågå et al. 1982; Hussein et al. 1988; Panth et al. 1990; Uotila et al. 1993; Rondo et al. 1995). Although levels of total lipid,

\footnotetext{
Abbreviations: Polyenes, polyunsaturated fatty acids; UI, unsaturation index.

*Present address: TNO Nutrition and Food Research Institute, Utrechtseweg 48, 3704 HE, Zeist, The Netherlands (PO Box 360, 3700 AJ, Zeist, The Netherlands).

$†$ Corresponding author: Dr R. P. Mensink, fax +31 433670 976, email r.mensink@hb.unimaas.nl
} 
lipoproteins, cholesterol and triacylglycerols are low also (Jagadeesan \& Prema, 1980b; Martinez et al. 1981; Hågå et al. 1982; Uotila et al. 1993), the previous prospective survey (Al et al. 1995) observed a higher proportion of highlyunsaturated fatty acids, e.g. arachidonic acid and docosahexaenoic acid, in umbilical-vein plasma phospholipids, as compared with maternal plasma phospholipids.

Thus, we have investigated maternal plasma levels of tocopherol isomers, several carotenoids, and retinol during the course of pregnancy and postpartum, and have compared these levels with the degree of fatty acid unsaturation. In addition, lipid-soluble antioxidant levels and fatty acid unsaturation were measured in umbilical cord plasma.

\section{Subjects and methods}

\section{Subjects and samples}

Plasma samples, with EDTA as an anticoagulant, were obtained from a study in which 140 pregnant women originally participated (Al et al. 1995). After analysis of the phospholipid-fatty acid patterns performed for that study, thirty-five complete sets of 1 st, 2 nd, and 3rd trimester maternal plasma samples, thirty-two postpartum maternal samples and twenty-seven concurrent umbilical-vein plasma samples were available for antioxidant analysis. The women were of Caucasian race, had singleton pregnancies, were normotensive, had no metabolic, cardiovascular, neurological or renal disorder, and did not develop gestational diabetes. The thirteen female and fourteen male infants were born at term and were appropriate for gestational age. The 1st, 2nd, and 3rd trimester plasma samples were collected at 14, 22, and 32 weeks of gestation respectively. Postpartum maternal and umbilical-vein (cord) plasma samples were taken immediately after delivery (Al et al. 1995). Plasma samples had been stored for 2-4 years at $-80^{\circ}$. A pilot study has shown that the concentration of the reported antioxidants is stable in plasma stored for 5 years at $-80^{\circ}$ (Oostenbrug, 1996).

\section{Methods}

Plasma antioxidants. Plasma was analysed by HPLC for tocopherol isomers $(\delta, \beta+\gamma$, and $\alpha$ ), carotenoids (phytofluene, lutein, lycopene, $\alpha$-carotene, $\beta$-carotene) and retinol (Hess et al. 1991; Oostenbrug et al. 1997). All samples from one subject and her neonate were analysed in the same analytical run. Since pure phytofluene was not available, quantitative determination of this compound was not possible. On a reversed-phase column, $\beta$-tocopherol coelutes with $\gamma$-tocopherol and, therefore, they are reported together. Twelve analyses of a mixture of antioxidant standards in six runs showed CV ranging from 2.4 to $3.6 \%$ for the various antioxidants. The mean recovery of the internal standard retinyl acetate added to plasma samples was 101 (SE 0.6) \%, and the detection limit in plasma samples was 0.003 $\mu \mathrm{mol} / \mathrm{l}$ for all antioxidants.

Plasma phospholipid-fatty acids. Details of the plasma phospholipid-fatty acid analysis have been reported previously (Al et al. 1995). Briefly, lipids were extracted from plasma using a modified Folch method. Then, the phospholipids were separated on aminopropyl-bonded silica columns, and saponified. The fatty acids were transmethylated with $\mathrm{BF}_{3}-$ methanol, and the corresponding methyl esters were quantified on a non-polar capillary column. Fatty acid unsaturation was estimated by calculating the polyunsaturated fatty acid (polyene) unsaturation index (UI) as the sum of the millimolar concentration of each polyene in the phospholipids multiplied with its number of double bonds. The UI of phospholipids was used since phospholipids are structural lipids very rich in polyenes. Moreover, changes in the oxidation-susceptible polyene levels are most pronounced in the phospholipid fraction (Holman, 1986).

Statistical analysis. The four serial maternal samples collected during the 1st, 2nd and 3rd trimester and postpartum, were compared by repeated-measures ANOVA using least-squares estimates of marginal means for unbalanced designs. Postpartum maternal and cord plasma samples were compared by paired Student's $t$ test and Spearman correlation coefficients. ANOVA residuals and maternal-neonatal differences were checked for normality by Shapiro-Wilk statistics, which confirmed normal distributions for most reported antioxidants (Table 1) and all fatty acids (Table 2). For the nonnormally-distributed antioxidants, $\delta$-tocopherol, $\alpha$-carotene and $\beta$-carotene, trends during pregnancy and maternalneonatal differences were also evaluated using the nonparametric Friedman test and signed rank test respectively. However, this revealed no essential differences from parametric statistical analysis. Thus, all $P$ values refer to parametric analyses. Maternal plasma levels were evaluated as compared with levels in the 1st trimester, and as compared with levels in the previous trimester. As this involved five simultaneous comparisons, the level of significance between moments of sampling was set at $P<0 \cdot 01$. To study whether neonatal antioxidant levels were related to maternal antioxidant levels before delivery, Spearman correlation coefficients were also computed between neonatal values and maternal values during each trimester. Spearman correlation coefficients were preferred since in one or two sets of maternal and neonatal plasma samples, antioxidant levels were considerably higher than those in the other sets, which largely affected Pearson correlation coefficients. Values are reported as means with their standard errors. All statistical analyses were performed using SAS 6.09 (Statistical Analysis Systems, 1989-1992).

\section{Results}

\section{Maternal plasma antioxidant levels during pregnancy}

Maternal plasma levels of $\delta$-tocopherol $(+74 \%), \beta+\gamma$-tocopherol $(+42 \%), \alpha$-tocopherol $(+46 \%)$, and lutein $(+41 \%)$ increased steadily from the 1 st trimester to the 3 rd trimester $(P<0 \cdot 001$; Table 1). $\beta$-Carotene levels decreased during pregnancy, and levels in the 3rd trimester were $20 \%$ lower than levels in the 1st trimester $(P=0 \cdot 003)$. Plasma levels of the other carotenoids did not significantly change during pregnancy (Table 1). Plasma retinol levels were decreased during the 3 rd trimester only $(P<0.0001)$. 
Table 1. Maternal and neonatal (cord) plasma antioxidant levels ( $\mu \mathrm{mol} / \mathrm{l})$ in normal pregnancy§

(Mean values with their standard errors for the no. of samples shown in parentheses)

\begin{tabular}{|c|c|c|c|c|c|c|c|c|c|c|c|c|}
\hline & \multicolumn{8}{|c|}{ Maternal level during gestation } & & & & \\
\hline $\begin{array}{l}\text { Tocopherols } \\
\delta \text {-Tocopherol } \\
\beta+\gamma \text {-Tocopherol } \\
\alpha \text {-Tocopherol }\end{array}$ & $\begin{array}{r}30 \cdot 18 \\
0 \cdot 17 \\
2 \cdot 75 \\
27 \cdot 26\end{array}$ & $\begin{array}{l}1 \cdot 11 \\
0 \cdot 02 \\
0 \cdot 17 \\
1 \cdot 04\end{array}$ & $\begin{array}{c}36 \cdot 62^{* *} \\
0.20 \\
3 \cdot 17 \\
33 \cdot 25^{\text {** }}\end{array}$ & $\begin{array}{l}1 \cdot 15 \\
0 \cdot 02 \\
0 \cdot 20 \\
1 \cdot 09\end{array}$ & $\begin{array}{c}42 \cdot 81^{* *}+\dagger \\
0 \cdot 24^{\star *} \\
3 \cdot 66^{\star *} \dagger \\
38 \cdot 90^{\star *}+\dagger\end{array}$ & $\begin{array}{l}1 \cdot 35 \\
0 \cdot 02 \\
0 \cdot 26 \\
1 \cdot 24\end{array}$ & $\begin{array}{c}41 \cdot 55^{\star *} \\
0 \cdot 17 \dagger \dagger \\
2 \cdot 79 \dagger \dagger \\
38 \cdot 59^{\star *}\end{array}$ & $\begin{array}{l}1 \cdot 82 \\
0 \cdot 01 \\
0 \cdot 19 \\
1 \cdot 77\end{array}$ & $\begin{array}{l}8.29 \ddagger \\
0.05 \ddagger \\
0.50 \ddagger \\
7 \cdot 74 \ddagger\end{array}$ & $\begin{array}{l}0.381 \\
0.007 \\
0.044 \\
0.357\end{array}$ & $\begin{array}{l}21 \cdot 8 \\
27 \cdot 7 \\
19 \cdot 9 \\
22 \cdot 0\end{array}$ & $\begin{array}{l}1 \cdot 8 \\
4 \cdot 3 \\
1 \cdot 7 \\
1 \cdot 8\end{array}$ \\
\hline $\begin{array}{l}\text { Carotenoids } \\
\text { Lutein } \\
\text { Lycopene } \\
\alpha \text {-Carotene } \\
\beta \text {-Carotene }\end{array}$ & $\begin{array}{l}1.46 \\
0.48 \\
0.62 \\
0.06 \\
0.30\end{array}$ & $\begin{array}{l}0.08 \\
0.03 \\
0.05 \\
0.01 \\
0.02\end{array}$ & $\begin{array}{l}1 \cdot 45 \\
0.57^{\star} \\
0.55 \\
0.06 \\
0.27\end{array}$ & $\begin{array}{l}0.07 \\
0.03 \\
0.03 \\
0.01 \\
0.02\end{array}$ & $\begin{array}{l}1.50 \\
0.65^{\star \star} \\
0.57 \\
0.05 \\
0.24^{\star}\end{array}$ & $\begin{array}{l}0.08 \\
0.04 \\
0.03 \\
0.00 \\
0.02\end{array}$ & $\begin{array}{l}1.46 \\
0.64^{\star \star} \\
0.48^{\star \star} \\
0.06 \\
0.28\end{array}$ & $\begin{array}{l}0.10 \\
0.04 \\
0.03 \\
0.01 \\
0.05\end{array}$ & $\begin{array}{l}0.23 \ddagger \\
0.15 \ddagger \\
0.04 \ddagger \\
0.01 \ddagger \\
0.03 \ddagger\end{array}$ & $\begin{array}{l}0.025 \\
0.018 \\
0.005 \\
0.001 \\
0.004\end{array}$ & $\begin{array}{r}17 \cdot 4 \\
25 \cdot 4 \\
8 \cdot 8 \\
18 \cdot 2 \\
15 \cdot 9\end{array}$ & $\begin{array}{l}1 \cdot 9 \\
3.0 \\
0.9 \\
2.5 \\
1.9\end{array}$ \\
\hline Phytofluene \| & 0.60 & 0.05 & 0.58 & 0.04 & 0.66 & 0.05 & 0.63 & 0.05 & $(0.00$ & $04) \neq \uparrow$ & & \\
\hline
\end{tabular}

$\mathrm{C}: \mathrm{PP}$, average value for cord : maternal postpartum levels, expressed as a percentage.

Mean values were significantly different from those for 1 st trimester (repeated measures ANOVA): ${ }^{*} P<0.01,{ }^{* *} P<0.001$.

Mean values were signifcantly different from those in the previous column (repeated measures ANOVA): $\dagger P<0.01, \dagger+P<0.001$.

Mean values were significantly different from maternal postpartum levels (Student's paired $t$ test): $\ddagger P<0.001$.

$\S$ For details of subjects and procedures, see p. 68.

$\|$ Phytofluene chromatogram peak areas are expressed in $\mathrm{mV} \times \mathrm{min} / \mu \mathrm{l}$ plasma $(\times 100)$.

- Only 5 cord samples contained detectable concentrations of phytofluene; range is shown in parentheses.

Immediately after delivery, maternal plasma $\alpha$-tocopherol and lutein levels remained increased, but $\delta$-tocopherol $(P=0.001$ v. 3rd trimester $)$ and $\beta+\gamma$-tocopherol $(P<$ $0.0001 v$. 3rd trimester) levels were lower than levels in the 3rd trimester, and similar to 1st trimester levels. Postpartum plasma lycopene levels were lower than 1st trimester levels $(P=0.0006$; Table 1$)$, but for $\alpha$-carotene, $\beta$-carotene and phytofluene, post- and prenatal levels were not significantly different.

\section{Comparison of changes in maternal plasma antioxidant levels during pregnancy with changes in plasma phospholipid-fatty acid unsaturation}

Maternal plasma levels of all fatty acids in the phospholipid fraction also increased during pregnancy. The $25 \%$ increase in polyunsaturated fatty acids in phospholipids resulted in a $22 \%$ increase in the polyene UI during pregnancy (Table 2 ).

Maternal plasma $\alpha$-tocopherol: UI values increased by

Table 2. Fatty acid composition ( $\mathrm{mmol} / \mathrm{l})$ and unsaturation index of maternal and neonatal (cord) plasma phospholipids in normal pregnancy§ (Mean values with their standard errors for no. of samples shown in parentheses)

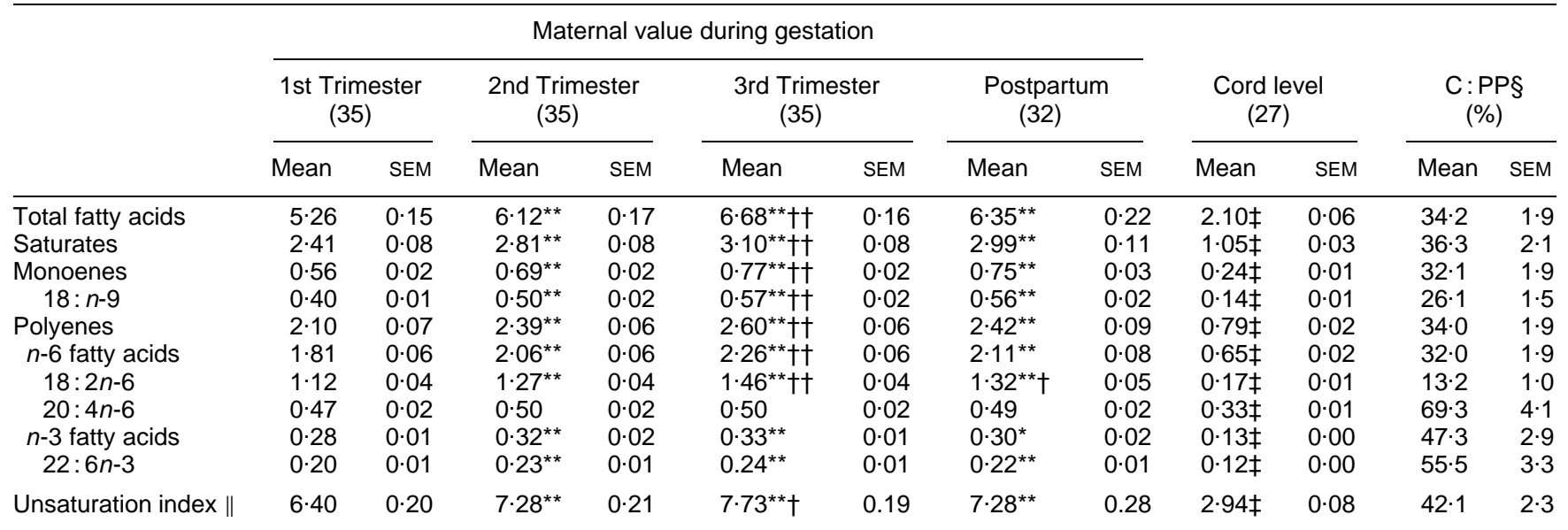

C : PP, average value for cord : postpartum maternal levels, expressed as a percentage; monoenes, monounsaturated fatty acids; polyenes, polyunsaturated fatty acids.

Mean values were significantly different from those for 1st trimester (repeated measures ANOVA): ${ }^{*} P<0.01,{ }^{* *} P<0.001$

Mean values were significantly different from those in the previous column (repeated measures ANOVA): $† P<0.01, \dagger \dagger P<0.001$

Mean values were significantly different from maternal postpartum levels (Student's paired $t$ test): $\ddagger P<0.001$.

$\S$ For details of subjects and procedures, see p. 68.

|| Calculated as the sum of the millimolar concentration of each polyene multiplied with its number of double bonds. 
$20 \%(P<0.0001)$ during pregnancy, despite the increase in UI (Table 3). On the other hand, values for lycopene: UI $(-17 \%, P<0.0001), \alpha$-carotene: UI $(-21 \%, P=0.0003), \beta$ carotene : UI $(-33 \%, P<0 \cdot 0001)$, and retinol : UI $(-33 \%, P<$ $0 \cdot 0001)$ decreased during pregnancy. Results were essentially similar when antioxidant levels were standardized for total fatty acid or total polyunsaturated fatty acids levels.

After delivery, maternal $\alpha$-tocopherol: UI values tended to be higher than corresponding values for 3rd trimester ratios $(P=0 \cdot 020)$, but this change did not reach the statistical significance level set at $P<0 \cdot 01$. All carotenoids : UI values after delivery were also similar to those in the 3rd trimester. However, $\delta$-tocopherol : UI $(P=0 \cdot 008)$ and $\beta+\gamma$ tocopherol: UI $(P=0 \cdot 0005)$ values were significantly lower after delivery as compared with 3rd trimester levels (Table 3). The decrease in retinol: UI observed in the 3rd trimester was partly normalized after delivery, but corresponding postpartum values were still lower than those in the 1st trimester $(P<0 \cdot 0001)$.

\section{Comparison of neonatal plasma antioxidant and}

phospholipid-fatty acid levels with maternal values

All cord samples had significantly lower levels of antioxidants than concurrent maternal samples $(P<0 \cdot 0001)$. Average cord levels of tocopherols and carotenoids were 9-28\% of maternal levels (Table 1). Although postpartum $\beta+\gamma$-tocopherol levels in maternal plasma significantly correlated with levels in cord plasma (Table 4), this was not the case for $\delta$-tocopherol and $\alpha$-tocopherol. Consequently, total tocopherol levels also did not correlate. With the exception of lycopene, carotenoid levels in postpartum maternal and cord plasma correlated significantly. In only five of twenty-seven cord samples, small traces of phytofluene could be detected and, therefore, correlation analysis was not performed. Cord retinol levels were on average $55 \%$ of maternal levels, but cord and maternal postpartum levels did not correlate. For $\beta+\gamma$-tocopherol, lutein, and $\beta$-carotene neonatal levels also consistently correlated with maternal levels before delivery (Table 4).

Total, saturated, monounsaturated, and total $n-6$ polyunsaturated phospholipid-fatty acid levels in cord plasma were on average $32-36 \%$ of maternal plasma levels. For total $n-3$ fatty acids, the mean cord value relative to the maternal value was $47 \%$. However, large differences between the individual fatty acids were present (Table 2). The polyene UI was on average only $42 \%$ of maternal postpartum values. Nonetheless, tocopherols: UI values and carotenoids: UI values were still significantly lower in cord samples as compared with postpartum maternal samples $(P<0 \cdot 0001$; Table 3). Retinol:UI values, however, were significantly higher than postpartum maternal values $(P=0 \cdot 0036)$.

\section{Discussion}

The present study investigated maternal plasma antioxidant levels during pregnancy and their relationships with neonatal antioxidant levels. In addition, antioxidant levels were analysed in relation to fatty acid unsaturation of plasma phospholipids.

Maternal plasma total tocopherol levels increased significantly during pregnancy, as has been reported for vitamin $\mathrm{E}$ (Hågå et al. 1982; Mino \& Nagamatu, 1986; Uotila et al. 1991), despite the large increase in plasma volume observed during the course of pregnancy (Lund \& Donovan, 1967). The increase in tocopherol levels was still observed when adjusted for the increase in plasma unsaturation, as estimated by the phospholipid-polyene UI. Thus, the increase

Table 3. Values for plasma lipid-soluble antioxidant levels : plasma phospholipid-polyunsaturated fatty acid unsaturation index in normal pregnancy§\|

(Mean values with their standard errors for the no. of samples shown in parentheses)

\begin{tabular}{|c|c|c|c|c|c|c|c|c|c|c|}
\hline & \multicolumn{8}{|c|}{ Maternal ratio during gestation } & & \\
\hline $\begin{array}{l}\text { Tocopherols } \\
\delta \text {-Tocopherol } \\
\beta+\gamma \text {-Tocopherol } \\
\alpha \text {-Tocopherol }\end{array}$ & $\begin{array}{l}4 \cdot 721 \\
0 \cdot 027 \\
0 \cdot 433 \\
4 \cdot 261\end{array}$ & $\begin{array}{l}0.088 \\
0.002 \\
0.026 \\
0.079\end{array}$ & $\begin{array}{l}5 \cdot 044^{*} \\
0.028 \\
0.438 \\
4 \cdot 577^{\star *}\end{array}$ & $\begin{array}{l}0.085 \\
0.003 \\
0.026 \\
0.084\end{array}$ & $\begin{array}{l}5.533^{\star *}+\dagger \\
0.031 \\
0.474 \\
5.027^{\star *}+\dagger\end{array}$ & $\begin{array}{l}0.099 \\
0.002 \\
0.031 \\
0.092\end{array}$ & $\begin{array}{l}5 \cdot 714^{\star *} \\
0 \cdot 024 \dagger \\
0 \cdot 387 \dagger \dagger \\
5 \cdot 302^{\star *}\end{array}$ & $\begin{array}{l}0.145 \\
0.002 \\
0.024 \\
0.147\end{array}$ & $\begin{array}{l}2 \cdot 816 \neq \ddagger \\
0 \cdot 016 \ddagger \ddagger \\
0 \cdot 169 \ddagger \ddagger \\
2 \cdot 632 \ddagger \ddagger\end{array}$ & $\begin{array}{l}0.089 \\
0.002 \\
0.012 \\
0.084\end{array}$ \\
\hline $\begin{array}{l}\text { Carotenoids } \\
\text { Lutein } \\
\text { Lycopene } \\
\alpha \text {-Carotene } \\
\beta \text {-Carotene }\end{array}$ & $\begin{array}{l}0.234 \\
0.076 \\
0.099 \\
0.010 \\
0.048\end{array}$ & $\begin{array}{l}0.013 \\
0.005 \\
0.007 \\
0.001 \\
0.004\end{array}$ & $\begin{array}{l}0.205^{\star} \\
0.081 \\
0.078^{\star *} \\
0.008 \\
0.038^{* *}\end{array}$ & $\begin{array}{l}0.010 \\
0.005 \\
0.005 \\
0.001 \\
0.003\end{array}$ & $\begin{array}{l}0.197^{\star \star} \\
0.085 \\
0.074^{\star \star} \\
0.007^{\star \star} \\
0.031^{\star \star} \dagger\end{array}$ & $\begin{array}{l}0.010 \\
0.005 \\
0.004 \\
0.001 \\
0.002\end{array}$ & $\begin{array}{l}0.202^{\star *} \\
0.089^{*} \\
0.068^{\star *} \\
0.008 \\
0.037^{\star *}\end{array}$ & $\begin{array}{l}0.011 \\
0.005 \\
0.005 \\
0.001 \\
0.005\end{array}$ & $\begin{array}{l}0.079 \ddagger \ddagger \\
0.052 \ddagger \ddagger \\
0.013 \ddagger \ddagger \\
0.003 \ddagger \ddagger \\
0.011 \ddagger \ddagger\end{array}$ & $\begin{array}{l}0.008 \\
0.006 \\
0.001 \\
0.000 \\
0.001\end{array}$ \\
\hline Phytofluene & 0.094 & 0.008 & 0.082 & 0.006 & 0.086 & 0.006 & 0.088 & 0.007 & \multicolumn{2}{|c|}{$(0.000-0.012) \ddagger \ddagger$} \\
\hline
\end{tabular}

Mean values were significantly different from those for 1 st trimester (repeated measures ANOVA): ${ }^{*} P<0.01,{ }^{* *} P<0.001$.

Mean values were significantly different from those in the previous column (repeated measures ANOVA): $\dagger P<0.01, \dagger \dagger P<0.001$.

Mean values were significantly different from maternal postpartum levels (Student's paired $t$ test): $¥ P<0.01, \neq \ddagger P<0.001$.

$\S$ For details of subjects and procedures, see p. 68.

$\|$ Values are expressed as $\mu \mathrm{mol}$ antioxidant/no. of double bonds per mmol polyenes (for details, see p. 68 and Tables 1 and 2 ).

q Only five cord samples contained detectable concentrations of phytofluene (range is given). 
Table 4. Spearman correlation coefficients between neonatal and maternal plasma antioxidant levels during pregnancy and postpartum

\begin{tabular}{|c|c|c|c|c|}
\hline & \multicolumn{3}{|c|}{ Gestational period } & \multirow[b]{2}{*}{ Postpartum } \\
\hline & 1st Trimester & 2nd Trimester & 3rd Trimester & \\
\hline $\begin{array}{l}\text { Tocopherols } \\
\delta \text {-Tocopherol } \\
\beta+\gamma \text {-Tocopherol } \\
\alpha \text {-Tocopherol }\end{array}$ & $\begin{array}{l}0.082 \\
0.169 \\
0.567^{\star \star} \\
0.077\end{array}$ & $\begin{array}{l}0 \cdot 041 \\
0 \cdot 121 \\
0 \cdot 473^{\star} \\
0 \cdot 013\end{array}$ & $\begin{array}{c}-0.002 \\
0.369 \\
0.658^{\star \star *} \\
-0.094\end{array}$ & $\begin{array}{c}-0.223 \\
0.299 \\
0.536^{\star \star} \\
-0.175\end{array}$ \\
\hline $\begin{array}{l}\text { Carotenoids } \\
\text { Lutein } \\
\text { Lycopene } \\
\alpha \text {-Carotene } \\
\beta \text {-Carotene }\end{array}$ & $\begin{array}{l}0.463^{\star} \\
0.703^{\star \star \star} \\
0.427^{\star} \\
0.228 \\
0.431^{\star}\end{array}$ & $\begin{array}{l}0.570^{\star *} \\
0.582^{* *} \\
0.363 \\
0.173 \\
0.603^{\star * \star}\end{array}$ & $\begin{array}{l}0.787^{\star \star \star} \\
0.854^{\star \star \star} \\
0.345 \\
0.344 \\
0.682^{\star \star \star}\end{array}$ & $\begin{array}{l}0.476^{\star} \\
0.534^{\star \star} \\
0.354 \\
0.484^{\star} \\
0.468^{\star}\end{array}$ \\
\hline Retinol & -0.002 & -0.059 & $0 \cdot 157$ & 0.236 \\
\hline
\end{tabular}

${ }^{*} P<0.05,{ }^{* *} P<0.01,{ }^{* * *} P<0.001$.

in phospholipid-polyunsaturated fatty acid levels during pregnancy did not compromise the vitamin E status.

Others have reported constant maternal plasma vitamin E levels during pregnancy, when standardized for total lipid (Mino \& Nagamatu, 1986), cholesterol (Jagadeesan \& Prema, 1980a; Uotila et al. 1991), or LDL (Hågå et al. 1982) concentrations, while triacylglycerol-standardized vitamin E levels decreased during pregnancy (Jagadeesan \& Prema, 1980a). Standardization for triacylglycerols, however, may be less important in view of potential oxidative stress, since the degree of unsaturation in triacylglycerols is relatively low (van der Schouw et al. 1991).

$\mathrm{Al}$ et al. (1995) suggested that the increase in maternal plasma phospholipid-polyunsaturated fatty acid levels could be due to increased mobilization from maternal stores. In this lipid environment, vitamin E may have been transported to the plasma also, although the increases in plasma vitamin E levels were larger than the increases in phospholipid-fatty acid levels. However, most carotenoid levels did not increase with phospholipid-fatty acid levels during pregnancy, and the antioxidant: UI value for these antioxidants decreased. It is unknown whether a difference in the capability to mobilize from stores may explain the differences between the response of the various antioxidants during pregnancy. Although the decrease in carotenoid: UI value during the course of pregnancy may have affected the antioxidant status, Davidge et al. (1992) reported that the antioxidant capacity of serum to inhibit autoxidation of brain homogenates in vitro steadily increased during pregnancy. Other studies, in which only total carotenoid levels were measured, have shown an increase (Panth et al. 1990) or no change (Morse et al. 1975) during pregnancy. This discrepancy may be due to the predominance of certain carotenoids in the diet of the populations studied. Our study showed, for example, that lutein levels increased, whereas $\beta$-carotene levels decreased during pregnancy (Table 1). In the present study, retinol levels were only decreased during the 3rd trimester as compared with the 1st and 2nd trimester and postpartum. Morse et al. (1975), however, found no change in maternal plasma vitamin A during pregnancy, whereas Panth et al. (1990) reported higher vitamin A levels at mid-gestation, as compared with early and late gestation, in low socio-economic class Indian women. They suggested that the decline during late gestation was due to the poor nutritional status of the women, or increased transfer of retinol across the placenta. In our study, the women were well-nourished (Al et al. 1996), but increased placental transfer may explain the sudden decrease during the 3rd trimester. However, it is unclear why this decrease was then no longer present after delivery. Furthermore, in another group of pregnant women studied at our department (Oostenbrug, 1996), postpartum retinol levels $(1.06 \mu \mathrm{mol} / \mathrm{l})$ were as low as 3rd trimester levels $(1.08 \mu \mathrm{mol} / \mathrm{l})$.

Several studies (Iioka et al. 1991; Uotila et al. 1991; Wang et al. 1991) have investigated whether the changes in antioxidant levels during pregnancy were sufficient to prevent peroxidation of the increased levels of polyunsaturated fatty acids, but results are conflicting. All investigators reported an increase in vitamin $\mathrm{E}$ levels during pregnancy and, indeed, Wang et al. (1991) found no increase in thiobarbituric acidreactive substances in serum. Iioka et al. (1991), however, reported a significant increase in plasma lipid peroxide levels during pregnancy. Uotila et al. (1991) found increased concentrations of conjugated dienes in serum only during the 2 nd trimester, while serum levels of thiobarbituric acid-reactive substances decreased non-significantly during pregnancy and fluorescent chromolipid levels did not change.

Postpartum, maternal plasma $\alpha$-tocopherol and carotenoid levels were similar to levels after 32 weeks of gestation. This was also found for vitamin E (Hågå et al. 1982), whereas others have reported that the increase in maternal $\alpha$-tocopherol levels during gestation continued until birth (Mino \& Nagamatu, 1986). Our study, however, showed that $\delta$ - and $\beta+\gamma$-tocopherol levels were lower immediately after delivery as compared with levels in the 3rd trimester. In a previous study in which oxidative stress was studied in patients undergoing percutaneous transluminal coronary angioplasty, we also noticed a decrease in only $\delta$ - and $\beta+\gamma$-tocopherol levels in LDL $2 \mathrm{~d}$ after the procedure, but no decrease in $\alpha$-tocopherol levels (Oostenbrug et al. 1997). However, the reason for the difference in response between the tocopherol isomers is still unclear.

Cord plasma contained lower antioxidant levels than maternal plasma, as has already been reported for vitamin $\mathrm{E}, \beta$-carotene, total carotenoids, and retinol (Jagadeesan \& Prema, 1980b; Martinez et al. 1981; Hågå et al. 1982; 
Hussein et al. 1988; Panth et al. 1990; Uotila et al. 1993; Rondo et al. 1995). Cord levels were also lower than maternal levels during early gestation. Although it has been suggested that the lower vitamin $\mathrm{E}$ levels in the newborn are due to low total lipid (Martinez et al. 1981) or LDL (Hågå et al. 1982) levels, in the present study cord total phospholipid-fatty acid-standardized tocopherol and carotenoid levels (results not shown) and UI-adjusted ratios were still significantly lower than maternal values. Consistent with our results, lipid-standardization of plasma vitamin E levels using cholesterol levels also revealed lower neonatal than maternal values (Jagadeesan \& Prema, 1980b). In our study, retinol levels in cord plasma were about half maternal levels. It is unknown, however, whether increased placental transfer during late gestation, as suggested by Panth et al. (1990), may explain the relative high cord levels of retinol as compared with the other antioxidants.

Lipid-soluble antioxidants act as important radical scavengers in lipophilic compartments, such as membranes, but several other compounds may also contribute to antioxidant defences (Niki, 1987). Although vitamin E belongs to the first line of antioxidant defence against lipid-soluble peroxyl radicals (Frei et al. 1992), vitamin C is capable of regenerating oxidized vitamin E (Iioka et al. 1991), while being consumed. In contrast to lipid-soluble antioxidant levels, however, vitamin $\mathrm{C}$ levels in umbilical vein plasma are higher than levels in maternal plasma (Guajardo et al. 1995). Nonetheless, the total antioxidant capacity of serum to inhibit autoxidation of brain homogenates is lower in neonates than in adults (Sullivan \& Newton, 1988). On the other hand, the total free-radical trapping ability of plasma is similar in term neonates and adults (Lindeman et al. 1989), and a low (Deligné et al. 1990) as well as high (Takehara et al. 1990) degree of lipid peroxidation has been reported in the newborn.

For total tocopherol (vitamin E), cord levels did not correlate with maternal levels, in agreement with other reports (Jagadeesan \& Prema, 1980b; Uotila et al. 1993). Shah et al. (1987), however, reported a significant correlation between cord and maternal levels in low-income and high-income Indian subjects. Although maternal levels in that study were only $60 \%$ of levels in the present study, average cord levels were similar or higher. This may indicate that vitamin E levels in cord blood are only influenced by maternal levels when these maternal levels are low. This is also supported by the higher correlation coefficient found in the low-income group with lower vitamin E levels, as compared with the high-income group (Takehara et al. 1990). In the present study, $\beta+\gamma$-tocopherol levels in cord and maternal plasma were well-correlated. However, the reason for the differences in neonatal-maternal correlation between the tocopherol isomers remains unclear.

For several carotenoids, cord plasma levels correlated with postpartum maternal levels. Although this suggests that carotenoids are concentration-dependently transferred from the mother to the child, this does not appear to be the case for lycopene, since correlation coefficients for this carotenoid were not significant. The low child: mother value for lycopene as compared with the other carotenoids $(9 \% v$. $16-25 \%$ ), also suggests a different transfer or metabolism of lycopene. Furthermore, the apparent absence of phyto- fluene in cord samples indicates that this carotenoid is not transferred from maternal to cord plasma at all. The absence of phytofluene in cord samples was not due to lack of sensitivity, since we are able to detect phytofluene levels which are 1000 times as low as average maternal levels.

Retinol levels in cord and maternal plasma did not correlate, as has been reported in Scandinavian (Uotila et al. 1993) and Brazilian (Rondo et al. 1995) populations. Studies from India (Shah \& Rajalakshmi, 1984) and Egypt (Hussein et al. 1988), however, reported a significant correlation between cord and maternal levels. Although average maternal retinol levels were lower in the latter studies $(0 \cdot 8-1 \cdot 1 \mu \mathrm{mol} / \mathrm{l})$ as compared with our study and the studies of Uotila et al. (1993) and Rondo et al. (1995) (1.3-1.7 $\mu \mathrm{mol} / \mathrm{l})$, Shah et al. (1987) found a higher correlation coefficient in a high-income group with higher retinol levels as compared with the low-income group.

In conclusion, the present study shows that during pregnancy the increase in maternal plasma phospholipid-fatty acid levels, and thus in peroxidation-susceptible polyunsaturated fatty acids and the UI, is accompanied by an equal or even larger increase in tocopherol levels, but that carotenoid levels do not increase concurrently. Furthermore, maternal plasma $\delta$ - and $\beta+\gamma$-tocopherol levels decrease after delivery, and umbilical cord levels of tocopherols and carotenoids are lower than maternal levels, even after correction for the lower polyunsaturated fatty acid content of plasma phospholipids in neonates. Additional studies are necessary to elucidate the mechanism of the reported changes in plasma antioxidant levels, and to show whether these changes may have physiological consequences.

\section{References}

Al MDM, Badart-Smook A, van Houwelingen AC, Hasaart THM \& Hornstra G (1996) Fat intake of women during normal pregnancy: relationship with maternal and neonatal essential fatty acid status. Journal of the American College of Nutrition $15,49-55$

Al MDM, van Houwelingen AC, Kester ADM, Hasaart THM, de Jong AEP \& Hornstra G (1995) Maternal essential fatty acid patterns during normal pregnancy and their relationship to the neonatal essential fatty acid status. British Journal of Nutrition 74, 55-68.

Davidge ST, Hubel CA, Brayden RD, Capeless EC \& McLaughlin MK (1992) Sera antioxidant activity in uncomplicated and preeclamptic pregnancies. Obstetrics and Gynecology 79, 897-901.

Deligné P, Bonnardot JP, Couderc R, Kerisit S, Périer JF \& Laruelle P (1990) Lipid peroxidation levels and antioxidant activities of blood plasma in parturients and new-born infants immediately after normal delivery. Advances in Experimental Medicine and Biology 264, 573-576.

Frei B, Stocker R \& Ames BN (1992) Small molecule antioxidant defences in human extracellular fluids. In Molecular Biology of Free Radical Scavenging Systems, pp. 23-45 [JG Scandalios, editor]. New York: Cold Spring Harbor Laboratory Press.

Guajardo L, Beharry KDA, Modanlou HD \& Aranda JV (1995) Ascorbic acid concentrations in umbilical cord veins and arteries of preterm and term newborns. Biology of the Neonate 68, 1-9.

Hågå P, Ek J \& Kran S (1982) Plasma tocopherol levels and vitamin E/beta-lipoprotein relationships during pregnancy and in cord blood. American Journal of Clinical Nutrition 36, 12001204. 
Hess D, Keller HE, Oberlin B, Bonfanti R \& Schüep W (1991) Simultaneous determination of retinol, tocopherols, carotenes and lycopene in plasma by means of high-performance liquid chromatography on reversed phase. International Journal of Vitamin and Nutrition Research 61, 232-238.

Holman RT (1986) Control of polyunsaturated acids in tissue lipids. Journal of the American College of Nutrition 5, 183-211.

Hussein L, El-Shawarby O, Elnaggar B \& Abdelmegid A (1988) Serum vitamin A and carotene concentrations among Egyptian fullterm neonates in relation to maternal status. International Journal of Vitamin and Nutrition Research 58, 139-145.

Iioka H, Akada S, Hisanaga H, Shimamoto T, Yamada Y, Moriyama IS \& Ichijo M (1991) Changes in plasma levels of lipid peroxide and vitamin E during pregnancy. Asia-Oceania Journal of Obstetrics and Gynaecology 17, 357-361.

Jagadeesan V \& Prema K (1980a) Plasma tocopherol and lipid levels in pregnancy and oral contraceptive users. British Journal of Obstetrics and Gynaecology 87, 903-907.

Jagadeesan V \& Prema K (1980b) Plasma tocopherol and lipid levels in mother and umbilical cord; influence on birth weight. British Journal of Obstetrics and Gynaecology 87, 908910.

Lindeman JHN, van Zoeren-Grobben D, Schrijver J, Speek AJ, Poorthuis BJHM \& Berger HM (1989) The total free radical trapping ability of cord blood plasma in preterm and term babies. Pediatric Research 26, 20-24.

Lund CJ \& Donovan JC (1967) Blood volume during pregnancy. Significance of plasma and red cell volumes. American Journal of Obstetrics and Gynecology 98, 394-403.

Martinez FE, Goncalves AL, Jorge SM \& Desai ID (1981) Brief clinical and laboratory observations. Vitamin $\mathrm{E}$ in placental blood and its interrelationship to maternal and newborn levels of vitamin E. Journal of Pediatrics 99, 298-300.

Mino M \& Nagamatu M (1986) An evaluation of nutritional status of vitamin $\mathrm{E}$ in pregnant women with respect to red blood cell tocopherol level. International Journal of Vitamin and Nutrition Research 56, 149-153.

Morse EH, Clarke RP, Keyser DE, Merrow SB \& Bee DE (1975) Comparison of the nutritional status of pregnant adolescents with adult pregnant women. I. Biochemical findings. American Journal of Clinical Nutrition 28, 1000-1013.

Niki E (1987) Antioxidants in relation to lipid peroxidation. Chemistry and Physics of Lipids 44, 227-253.

Oostenbrug GS (1996) Lipid peroxidation and antioxidants in humans. Effects of oxidative stress and dietary $n-3$ fatty acids. $\mathrm{PhD}$ Thesis, Maastricht University, The Netherlands.
Oostenbrug GS, Mensink RP, Bär FWHM \& Hornstra G (1997) Lipid peroxidation-associated oxidative stress during percutaneous transluminal coronary angioplasty in humans. Free Radical Biology and Medicine 22, 129-136.

Panth M, Shatrugna V, Yasodhara P \& Sivakumar B (1990) Effect of vitamin A supplementation on haemoglobin and vitamin A levels during pregnancy. British Journal of Nutrition 64, 351358.

Rondo PHC, Abbott R, Rodrigues LC \& Tomkins AM (1995) Vitamin A, folate, and iron concentrations in cord and maternal blood of intra-uterine growth retarded and appropriate birth weight babies. European Journal of Clinical Nutrition 49, 391-399.

Shah RS \& Rajalakshmi R (1984) Vitamin A status of the newborn in relation to gestational age, body weight, and maternal nutritional status. American Journal of Clinical Nutrition 40, 794800.

Shah RS, Rajalakshmi R, Bhatt RV, Hazra MN, Patel BC, Swamy NB \& Patel TV (1987) Vitamin E status of the newborn in relation to gestational age, birth weight and maternal vitamin $\mathrm{E}$ status. British Journal of Nutrition 58, 191-198.

Statistical Analysis Systems (1989-1992) SAS 6.09 User's Guide, Statistics. Cary, NC: SAS Institute Inc.

Sullivan JL \& Newton RB (1988) Serum antioxidant activity in neonates. Archives of Disease in Childhood 63, 748-757.

Takehara Y, Yoshioka T \& Sasaki J (1990) Changes in the levels of lipoperoxide and antioxidant factors in human placenta during gestation. Acta Medica Okayama 44, 103-111.

Uotila J, Tuimala R, Aarnio T, Pyykkö K \& Ahotupa M (1991) Lipid peroxidation products, selenium-dependent glutathione peroxidase and vitamin E in normal pregnancy. European Journal of Obstetrics and Gynecology and Reproductive Biology 42, 95-100.

Uotila J, Tuimala R, Pyykkö K \& Ahotupa M (1993) Pregnancyinduced hypertension is associated with changes in maternal and umbilical blood antioxidants. Gynecologic and Obstetric Investigation 36, 153-157.

van der Schouw YT, Al MDM, Hornstra G, Bulstra-Ramakers MTEW \& Huisjes HJ (1991) Fatty acid composition of serum lipids of mothers and their babies after normal and hypertensive pregnancies. Prostaglandins Leukotrienes and Essential Fatty Acids 44, 247-252.

Wang YP, Walsh SW, Guo J \& Zhang J (1991) Maternal levels of prostacyclin, thromboxane, vitamin E, and lipid peroxides throughout normal pregnancy. American Journal of Obstetrics and Gynecology 165, 1690-1694. 